\title{
A review of the genus Alcathousiella Monné, 2005 (Coleoptera, Cerambycidae)
}

\author{
Francisco E. de L. NASCIMENTO ${ }^{1, *}$, Miguel A. MONNÉ ${ }^{2} \&$ James E. WAPPES $^{3}$ \\ ${ }^{1}$ LAC- Laboratório de Coleoptera do Museu de Zoologia da Universidade de São Paulo, \\ São Paulo, SP, Brazil, 04263-000. \\ ${ }^{2}$ Museu Nacional, Universidade Federal do Rio de Janeiro, Quinta da Boa Vista s/n, \\ São Cristovão, RJ, Brazil, 20940-040. \\ ${ }^{3}$ Deceased [January 11, 2021]. Former address: American Coleoptera Museum, \\ 8734 Paissano Pass, TX 78255-3253, USA. \\ *Corresponding author: eribnascimentofl@gmail.com \\ ${ }^{2}$ Email: monne@uol.com.br \\ $1 \odot$ https://orcid.org/0000-0002-5047-8921 \\ $2 \odot$ https://orcid.org/0000-0001-8825-3122 \\ ${ }^{1}$ urn:lsid:zoobank.org:author:79BCCF99-47FE-4FE7-9077-A2ADCA45130D \\ ${ }^{2}$ urn:lsid:zoobank.org:author:7AE99463-7ABC-465F-9B15-875AB7C70A20 \\ ${ }^{3}$ urn:1sid:zoobank.org:author:84274638-E41E-4DF8-9831-AC253ED9E32C
}

\begin{abstract}
The Acanthocinini genus Alcathousiella Monné, 2005 (Coleoptera, Cerambycidae, Lamiinae) is revised with both the genus and the type species, Alcathousiella polyrhaphoides (White, 1855) redescribed. New country records for the species, greatly expanding its known distribution in South America, are also presented. Lastly, Alcathousiella giesberti sp. nov., from Nicaragua, Costa Rica and Panama is described and illustrated.
\end{abstract}

Keywords. Central America, distribution, Neotropical region, new species, taxonomy.

Nascimento F.E. de L., Monné M.A. \& Wappes J.E. 2021. A review of the genus Alcathousiella Monné, 2005 (Coleoptera, Cerambycidae).European Journal of Taxonomy 757:37-49. https://doi.org/10.5852/ejt.2021.757.1411

\section{Introduction}

Currently, Alcathousiella Monné, 2005 is a monotypic genus with the type species, A. polyrhaphoides (White, 1855) distributed in northern South America and part of Central America (Tavakilian \& Chevillotte 2020). The diagnostic characteristics of the genus are the scape with an apical projection and the modified antennomere III in males, which is mentioned throughout its taxonomic history.

Originally, White (1855) proposed Alcidion polyrhaphoides White, 1855 and described the scape of his new species as being gibbose apically and with an apical spine: "Antennarum articulo basali ante apicem gibboso, articulo tertio apice intus unidentato". 
Bates (1863) transferred the species to Amniscus Dejean, 1835 and proposed that Amniscus polyrhaphoides should be cited as the type species of this genus. Still, according to Bates (1863): “...The joint [scape], although abruptly clavate, is of the same relative length as in the rest of the allied genera, and its presence also, near the tip on the underside, the small dentiform process which is characteristic of the subtribe".

Subsequently, this species was placed in a new genus, Alcathous Thomson, 1864. Regarding the shape of the scape, Thomson (1864) stated (translated): "art. 1 with apical third nearly equal to or slightly wider, then constricted and with a prolonged spine...". Although Thomson (op. cit.) did not explicitly state why he established a new genus for the species, we can assume, since it was used as a primary character in his identification key, that the rather unique shape of the scape was instrumental in doing so.

Finding that the name Alcathous was preoccupied by Alcathous Stål, 1863 (Hemiptera), Monné (2005) replaced it with Alcathousiella. The genus has since been associated (Nascimento \& Botero 2019) with a group of genera of Acanthocinini Blanchard, 1845 (Alcathousiella Monné, 2005, Amniscites Gilmour, 1955, Odontozineus Monné, 2009, Xenocona Gilmour, 1960 and Xenostylus Bates, 1885) with the following characters: antennomeres III-XI elongated, elytra without erect setae and without lateral carinae, elytra with central basal crest, with or without erect setae on apex, mesoventral process without tubercle, antennomere III with internal apical spine in the males. In their paper they redefined the above genera and provided a key to separate them.

In this contribution, we review the genus, its type species and describe a new species, Alcathousiella giesberti sp. nov., endemic to Central America. Figures, distribution maps and considerations about the evolution of the group are also provided.

\section{Material and methods}

The photographs were taken at MZSP (Museu de Zoologia, Universidade de São Paulo, São Paulo, Brazil), with a Canon EOS Rebel T3i DSLR camera (Taichung, Taiwan), Canon MP-E $65 \mathrm{~mm} \mathrm{f} / 2.8$ 1-5× macro lens, controlled by Zerene Stacker AutoMontage software (http://zerenesystems.com/cms/stacker). The measurements were taken in millimetres with an ocular Hensoldt/Wetzlar-Mess 10 (Taufkirchen, Germany) in the Leica MZ6 stereo microscope (Wetzlar, Germany). The photographs were edited in GIMP (GNU Image Manipulation Program) software. The figures were built in Inkscape 0.48.4. The maps were made through the ArcGIS ESRI software ver. 9.3. The morphological terms follow Lawrence et al. (2010). The taxonomic and distributional data follows Monné (2020) and Tavakilian \& Chevillotte (2020). A photograph of one syntype specimen, available on the Bezark's (2020) were checked. For dissection, the abdomen of the dry specimen was removed and heated in $10 \% \mathrm{KOH}$ solution for approximately 2 minutes with the genital parts removed through a cut on one side of the abdomen. The genitalia were reheated in the same solution for approximately 1 minute. The structures were then washed in acetic acid, the abdomen glued back on the specimen and the extracted genitalia stored in glycerin microvials.

\section{Repositories}

$\mathrm{AACP}=$ Alain Audureau private collection, St Gilles Croix de Vie, France

ACMT = American Coleoptera Museum (James Wappes), San Antonio, Texas, USA

$\mathrm{BMNH}=$ Natural History Museum (formerly British Museum: Natural History), London, United Kingdom

BYUC = Brigham Young University, M.L. Bean Life Science Museum, Provo, Utah, USA

CSCA = California State Collection of Arthropods, Sacramento, California, USA

DJHC = Daniel J. Heffern collection, Houston, Texas, USA

DZUP = Coleção de Entomologia Pe. Jesus Santiago Moure, Departamento de Zoologia, Universidade Federal do Paraná, Paraná, Brazil 


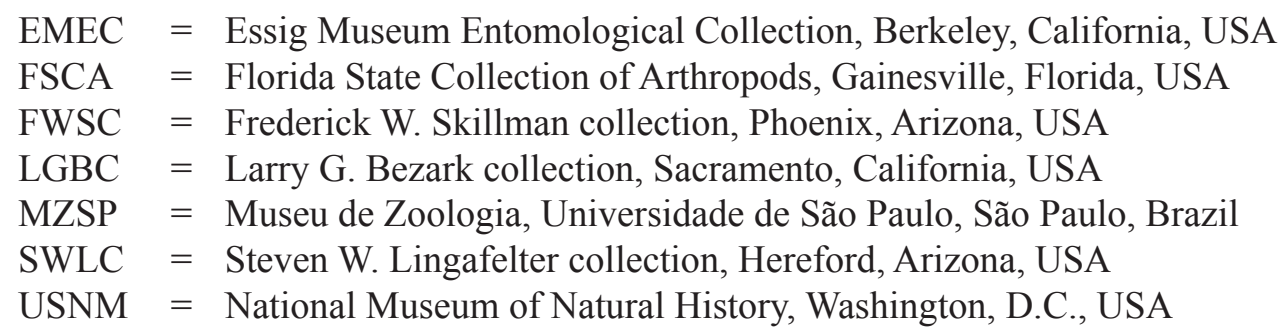

\section{Results}

Class Insecta Linneaus, 1758

Subphylum Hexapoda Blainville, 1816

Order Coleoptera Linnaeus, 1758

Suborder Polyphaga Emery,1886

Superfamily Chrysomeloidea Latreille, 1802

Family Cerambycidae Latreille, 1802

Subfamily Lamiinae Latreille, 1825

Tribe Acanthocinini Blanchard, 1845

Genus Alcathousiella Monné, 2005

Alcathousiella Monné, 2005: 11.

Amniscus Bates, 1863: 103 (not Dejean, 1835).

Alcathous Thomson, 1864: 24, type species Alcidion polyrhaphoides White, 1855 (original designation); not Alcathous Stål, 1863 (Hemiptera).

Alcathous - Thomson 1865: 353. - Monné 1995: 43.

Amniscus - Lacordaire 1872: 761.

Alcathousiella - Monné 2012: 66.

\section{Differential diagnosis}

Among the genera of Acanthocinini with modified antennomere III (Fig. 14), Alcathousiella can be distinguished by the scape strongly pedunculate-clavate with a spiniform projection at the inner side of the apex.

\section{Redescription}

\section{Male}

Head. As long as wide; lower eyes lobes slightly longer than genae; upper eyes lobes separated by about twice width of an upper eye lobe. Antennal tubercles strongly elevated distally from middle. Median groove distinct from clypeus to area behind upper eyes lobes, posteriorly covered by anterior margin of prothorax. Antennae filiform, 11-segmented, longer than body in both sexes. Scape pedunculatedclavate, clave starting at posterior third; reaching humeral area of elytra, inner side of apex with a spine-shaped projection in both sexes. Apex of antennomere III in males, with an internal spine-shaped projection.

ThORax. Pronotum with dense greyish pubescence; with five prominent tubercles, four broadly rounded (two larger at anterior half and two smaller ones posteriorly) and one, elongate and postmedian. Punctures arranged in transverse rows on anterior and posterior margins (at posterior margin, obliquely converging towards middle). Additional punctures scattered throughout pronotal disk. Sides of prothorax with prominent median conical tubercle. Prosternum micropunctate, moderately densely pubescent. 
Metaventrite in males with dense erect setae obscuring integument (setae can also extend to middle of abdominal ventrite I). Prosternal process usually $1 / 3$ procoxal width; mesoventral process slightly wider than half of mesocoxal diameter.

ELYTRA. Lacking erect setae; pubescence nearly obscuring integument, generally forming symmetrical patterns. Elytral surface with small tubercles on anterior third; anterior fifth with central basal crest; prominent basal crest with an erect tuft of setae apically; prominent area surrounding central basal crest rounded with small tubercles. Humeri rounded.

Legs. Femora strongly pedunculate-clavate; meso and metafemora with peduncles about as long as claves; profemora with short peduncle; tibiae elongate, slightly widened toward apex. Protarsomeres in males with dense bristly setae; metatarsomere I equal to or slightly longer than remaining metatarsomeres together.

ABDomen. Male with ventrite $\mathrm{V}$ deeply semicircularly notched and projected as minute spine; tergite $\mathrm{V}$ slightly notched or subtruncate.

\title{
Female
}

Antennomere III lacking acute internal spine at apex. Abdominal ventrite V, gradually narrowed from base to apex, apex subtruncate; tergite V acute apically, slightly surpassing the elytral apices. Protarsomere lacking dense bristly setae.

\author{
Alcathousiella giesberti sp. nov. \\ urn:Isid:zoobank.org:act:88FB5CC0-92B6-498D-A7A9-5C2A99C25F29
}

Figs $1-4,12,16-19$

Alcathousiella polyrhaphoides - Maes et al. 2010: 394. — Swift et al. 2010: 35.

\section{Differential diagnosis}

This species is characterized by the triangularly projected (Fig. 16) outer angle of elytra, protarsomeres in males with less dense, elongate blackish setae (Fig. 12), and by the less thickened femoral claves.

\section{Etymology}

The epithet is a noun in the genitive case to honour and recognize Edmund F. Giesbert (1931-1999), a remarkably talented, self-taught cerambycid taxonomist and artist.

\section{Material examined}

\section{Holotype}

COSTA RICA • ○’; Puntarenas, Monteverde; 1 Feb. 1978; E. Giesbert leg.; FSCA.

\section{Paratypes}

COSTA RICA • 2 우; same collection data as for holotype; FSCA • 1 q ; same collection data as for

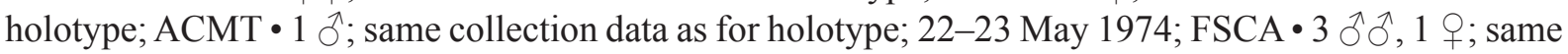
collection data as for holotype; 3-5 Jun. 1974; FSCA $-2 \hat{\partial} \bar{\partial}, 1$ क ; same collection data as for holotype;

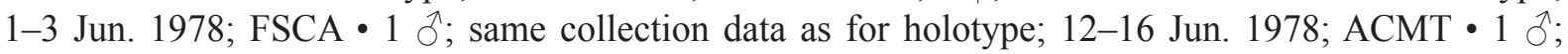
same collection data as for holotype; 4-6 Jun. 1980; FSCA • 1 त ; same collection data as for holotype;

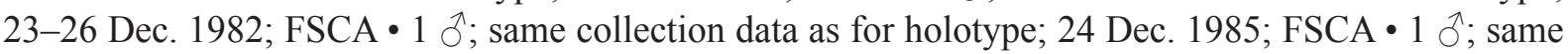
collection data as for holotype; 8 Jun. 1986; FSCA 1 \%; same collection data as for holotype; 24 Feb. 1985; FSCA • 1 \% ; same collection data as for holotype; 23-27 May 1987; FSCA • 1 q ; same collection data as for holotype; 19 Feb. 1988; F.D. Parker leg.; LGBC • 1 \% ; same collection data as for holotype; 19-26 May 1988; FSCA • 1 क; same collection data as for holotype; 4-9 Jan. 1989; F.T. Hovore leg.; 

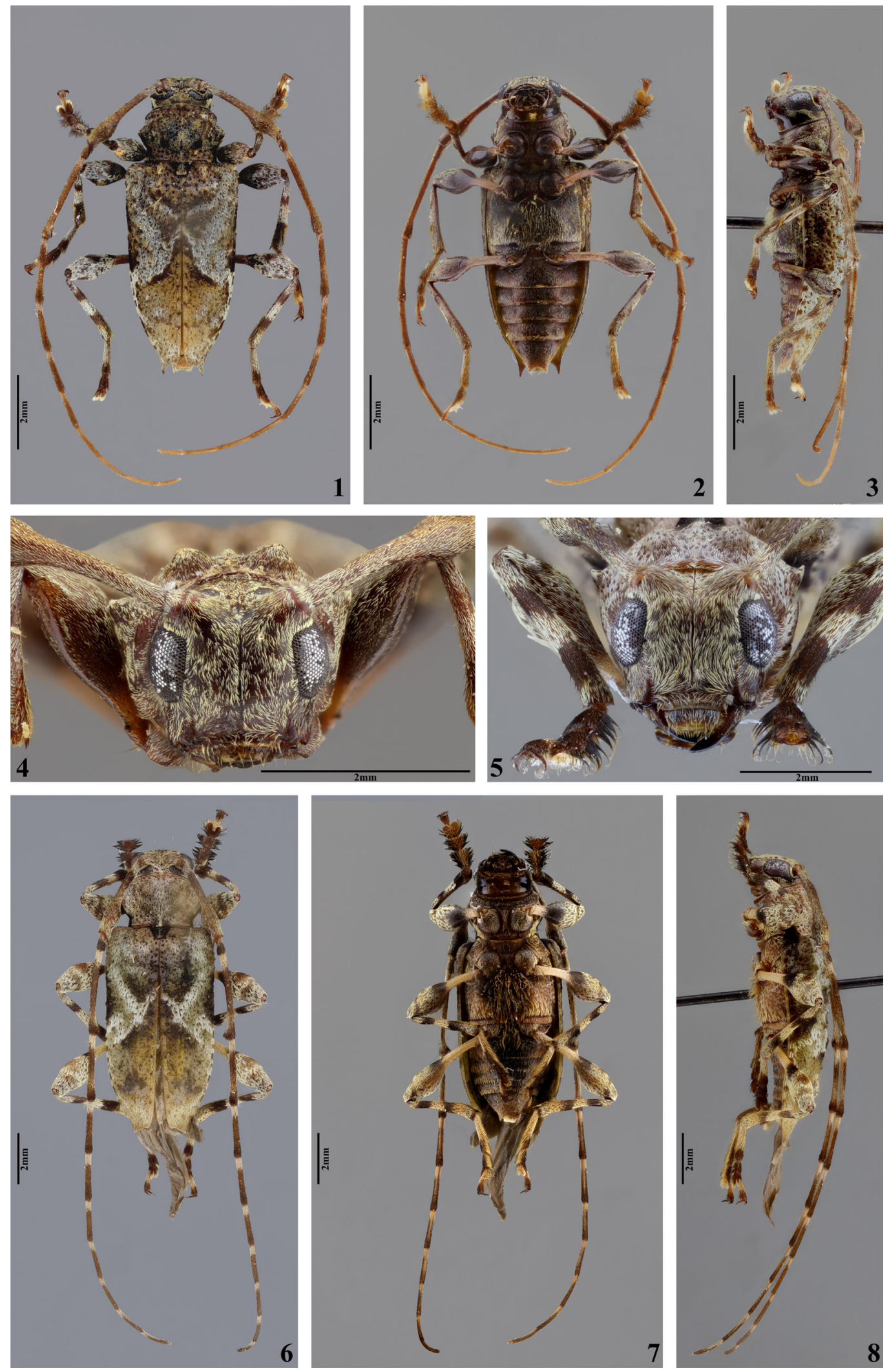

Figs 1-8. 1-4. Alcathousiella giesberti sp. nov. Holotype, §ิ (FSCA). 1. Dorsal habitus. 2. Ventral habitus. 3. Lateral habitus. 4. Head, frontal view. 5-8. Alcathousiella polyrhaphoides White, 1855. Males from Bolivia (FSCA). 5. Head, frontal view. 6. Dorsal habitus. 7. Ventral habitus. 8. Lateral habitus. 
LGBC • 1 đ̆; same collection data as for holotype; 12-15 Jun. 2002; Chemsak and Hovore leg.; LGBC

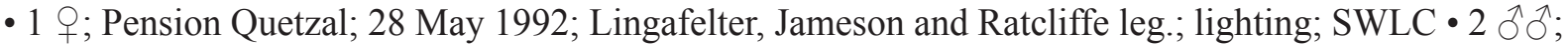
San Luis, Monteverde; $3900 \mathrm{ft}$; 12-13 May 1996; J. Wappes leg.; ACMT • 1 क; same collection data as for preceding; 12-15 Jun. 1996; F.T. Hovore leg.; CSCA $\bullet 1$ ô; same collection data as for preceding; 7 Jan. 1986; W. Haber leg.; EMEC • 1 o; same collection data as for preceding; 1 Feb. 1986; EMEC •

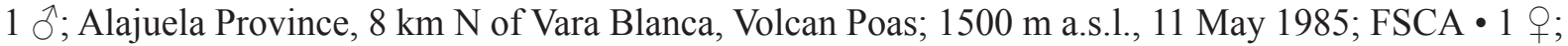
same collection data as for preceding; EMEC • 1 क; Catargo, Turrialba, CATIE; Dec. 1990; F.T. Hovore

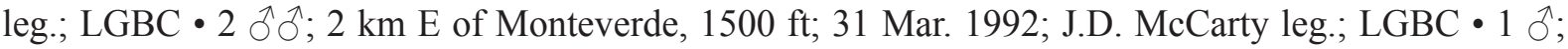
Alajuela Province, Bosque Nubosa, Monteverde; 8-11 Jan. 2005; C. Neuman leg.; LGBC.

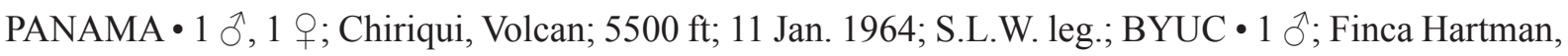
Ojo de agua; 8 $8^{\circ} 1^{\prime} 41^{\prime \prime} \mathrm{N}, 82^{\circ} 44^{\prime} 36^{\prime \prime} \mathrm{W}$; 1500+ m a.s.1., 11-14 Apr. 2018; B.T. Raber leg.; DJHC •

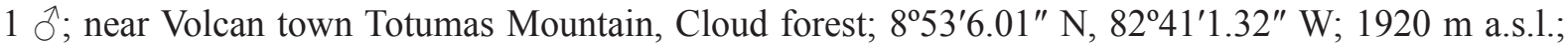
May-Jun. 2018; A. Kozlov and Kovaleva leg.; MZSP • 1 q; same collection data as for preceding; 1920-2200 m a.s.l.; May-Jun. 2019; A. Kozlov and Kovaleva leg; MZSP.

\section{Additional material}

NICARAGUA • 1 đ̊; Jinotega, San Rafael del Norte, Res. Sil. Priv. El Jaguar; 20-29 May 2017; P. Rouche leg.; AACP.

\section{Description}

\section{Holotype male}

MEAsurements (in mm). Total length, 8.3; prothorax length, 1.5; prothorax width, 2.4; elytral length, 6.0; humeral width, 3.1.

COLORATION. Integument mostly brownish; posterior half of prothorax sides and femoral claves dark brown; margin of abdominal ventrites, mouthparts (except mandibles, dark brown, blackish toward extremities) and femoral peduncles yellowish brown; posterior third of elytra yellowish brown.

HEAD. Frons finely densely, punctate; with moderately dense whitish-yellow pubescence, nearly obscuring integument; vertex with pubescence and punctures as on frons. Lower eye lobes about 1.3 the genal length; lobes connected by 3-4 rows of ommatidia. Upper eye lobes separated by twice upper eye lobe width. Labrum with moderately dense yellowish pubescence, not obscuring integument. Gulamentum sparsely punctate and minutely, sparsely pubescent. Antennae reaching elytral apex at the middle of antennomere V; scape long, slightly exceeding posterior margin of prothorax; with dense yellowish pubescence partially obscuring integument. Pedicel slightly widened posteriorly. Antennomeres slightly widened apically, evenly covered by yellowish pubescence. Antennal formula based on antennomere III: scape $=1.00 ;$ pedicel $=0.18 ; \mathrm{IV}=0.70 ; \mathrm{V}=0.50 ; \mathrm{VI}=0.50 ; \mathrm{VII}=0.40 ; \mathrm{VIII}=0.40 ; \mathrm{IX}=0.40 ; \mathrm{X}=$ $0.37 ; \mathrm{XI}=0.30$.

Thorax. Prothorax, across lateral tubercles, about 1.5 times as wide as long; pronotum coarsely punctate between tubercles; surface mostly covered by yellowish pubescence, especially between tubercles of the disk; posterior half with four circular spots of brown pubescence: two small laterally, near the middle and two larger behind posterior lateral tubercles. Sides with longitudinal fascia of brownish pubescence. Prosternal process $1 / 4$ width of procoxal cavity. Mesoventral process about 0.5 the diameter of mesocoxal cavity; greyish pubescent. Metaventrite minutely punctate; broad triangular area centrally with dense erect yellowish setae, obscuring integument; laterally with dense yellowish pubescence. Mesanepisternum, mesepimeron, metanepisternum and metepimeron with yellowish pubescence interspersed by brownish pubescence. Scutellum truncate posteriorly, covered with dark pubescence laterally and medially with a central yellowish pubescent area. 

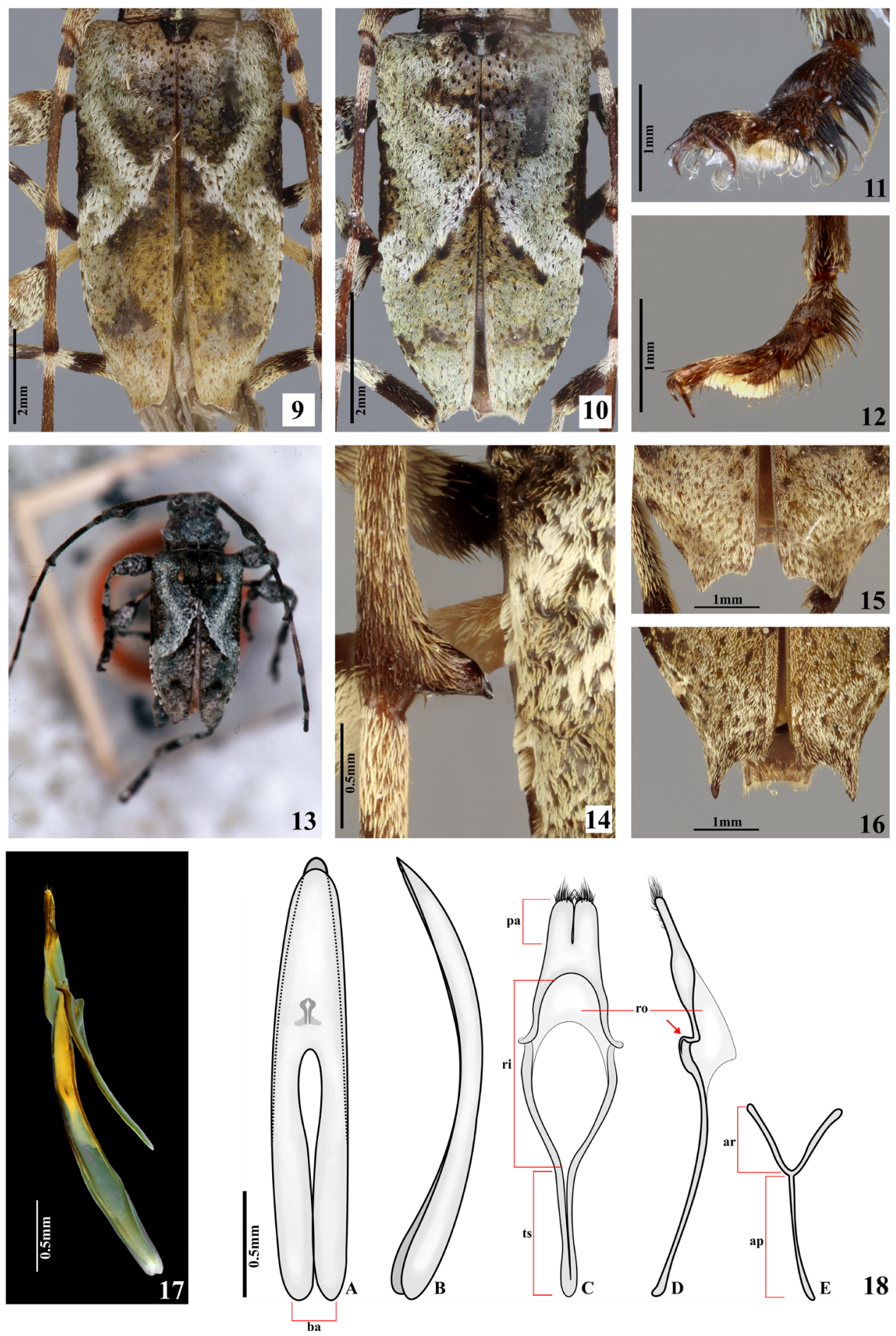

18

Figs 9-18. 9-11, 3-15. Alcathousiella polyrhaphoides (White, 1855) (FSCA). 9-10. Elytral pubescence pattern. 9. Male 1. 10. Male 2. 11. Detail of protarsomeres. 13. Slide of one of the syntype specimens $(\mathrm{BMNH})$, deposited at Coleção de Imagens de material-tipo J.S. Moure (DZUP). 14. Male antennomere III with internal spine. 15. Detail of distal $1 / 3$ of elytra. 12, 16-18. A. giesberti sp. nov. (FSCA). 12. Detail of protarsomeres. 16. Detail of distal third of elytra. 17. Male genitalia in lateral view. 18. Schemes of male genitalia: $\mathrm{A}=$ median lobe in dorsal view; $\mathrm{B}=$ median lobe in lateral view; $\mathrm{C}=$ tegmen in dorsal view; $\mathrm{D}=$ tegmen in lateral view; $\mathrm{E}=$ sternite VIII. Abbreviations: $\mathrm{ap}=$ apophysis; $\mathrm{ar}=\mathrm{arms}$; $\mathrm{ba}=$ basal apophyses; $\mathrm{pa}=$ parameres; $\mathrm{ri}=$ ring part; $\mathrm{ro}=$ roof; $\mathrm{ts}=$ tegmen struts. 
ElYTRA. Sides gradually, slightly convergent at anterior two thirds, posterior third more strongly convergent toward apex; humeri slightly projected. Elytral suture longitudinally sulcate, apex strongly projected laterally much less so at sutural angle. Centro-basal crest elevated, with thick erect brownish tuft of setae apically. Surface, coarsely punctate, punctures sparser at posterior half. Pubescence (from anterior to posterior) as follows: greyish white band from humeri converging posteriorly towards the suture at elytral middle (not reaching it), then with a narrowed band converging anteriorly (reaching the suture); narrower band from humeri converging posteriorly at anterior third, forming an uneven triangular shaped area with brownish pubescence; large greyish band diverging from middle to epipleura at posterior third; posterior third mostly covered by yellowish pubescence; with irregular areas of greyish pubescence, especially toward apex; posterior elytral fifth with M-shaped area of brownish band.

Legs. Tibiae with greyish pubescence proximally, with brownish pubescence at apical third. Protarsi densely fringed laterally with brownish setae; metatarsomere I slightly longer than the remaining tarsomeres together.

ABDomen. Ventrites with sparse greyish pubescence.

Male Genitalia. Tegmen 3.8 times as long as wide (Fig. 18C-D). Tegminal ring about half the total tegmen length; in lateral view, strongly twisted downward at posterior third (Fig. 18D); strongly triangularly notched towards tegminal struts; tegminal struts about a third of the total tegmen length; parameres about 0.1 the total tegmen length, contiguous and parallel to each other; apex and ventral region with erect setae. Median lobe 5.7 times longer than wide; 1.15 times as long than tegmen; strongly arched in lateral view (Fig.18A-B), basal apophyses 0.57 times the total median lobe length. Sternite VIII with apophysis 1.6 times as long as length of arm (Fig. 18E).

Range of measures (in mm, male/female)

Total length, 8.3-10.5/8.5-11.7; prothorax length, 1.5-2.0/1.5-2.2; prothorax width, 2.4-3.1/2.2-3.4; elytral length, 6.0-7.5/6.4-8.6; humeral width, 3.1-4.0/3.1-4.5.

\section{Distribution}

Nicaragua, Costa Rica and Panama (Fig. 19).

\section{Remarks}

Alcathousiella giesberti sp. nov. and A. polyrhaphoides have rather similar pubescent elytral patterns. However, the new species can be differentiated from the latter by its strongly triangularly projected outer angle of the elytra (thorn shaped), by the male protarsomeres less densely edged with bristly setae, which is shorter and brownish; and by the less thickened femoral claves. In A. polyrhaphoides the outer angle of elytral apices is triangularly projected (Fig. 15), the protarsomeres in males have denser, longer blackish setae (Fig. 11), and the femoral claves are thicker. Besides morphological their geographical distribution also differs. Alcathousiella giesberti sp. nov. is restricted to Central America, while A. polyrhaphoides occurs in South America (Fig. 19). By the elytral apex of the species identified and figured as A. polyrhaphoides by Maes et al. (2010), it is possible to note that this species is actually A. giesberti sp. nov. Likewise, the species identified as A. polyrhaphoides by Swift et al. (2010) for Costa Rica, is $A$. giesberti sp. nov. (These specimens are figured at Bezark 2020). In a specimen from Panama, the elytral apex projection is less acute (similar to A. polyrhaphoides), however, the length and density of the protarsomeres setae and the thickness femoral claves, clearly indicate that it is the new species. The genitalia morphology of males of the two species is extremely similar and characters have not been found to separate them. 
Alcathousiella polyrhaphoides (White, 1855)

Figs 5-8, 9-11, 13-15, 19

Alcidion polyrhaphoides White, 1855: 394.

Amniscus polyrhaphoides - Bates 1863: 103. - Lacordaire 1872: 762.

Alcathous polyrhaphoides - Thomson 1864: 24. — Chemsak et al. 1992: 133.

\section{Differential diagnosis}

This species is characterized by the triangularly projected (Fig. 15) outer angle of elytra, protarsomeres in males with dense, longer blackish setae (Fig. 11), and by the thicker femoral claves.

\section{Material examined}

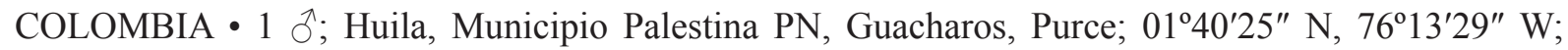
2200 m a.s.l.; Viktor Sinyaev leg.; MZSP • 1 क ; Valle del Cauca, 4 km NW San Antonio; 6500 ft; 20 Oct. 1958; A.H. Miller leg.; EMEC.

VENEZUELA • 1 đ; Aragua, Rancho Grande; 1100 m a.s.1.; 25-26 Jan. 1978; J.B. Heppner leg.; cloud forest; blacklight trap; USNM • 1 $\delta$; same collection data as for preceding; 17-20 Jan. 1978; USNM • 1 ; ; same collection data as for preceding; 8 May 1973; Günther Ekis leg.; USNM・ 1 ; ; same collection data as for preceding; 30-31 May 1988; M. Epstein leg.; UV light trap.; USNM • 1 đ; same collection data as for preceding; 7 Sep. 1967; J. Salcedo and L. Rodriguez leg; MZSP • 1 ㅇ; Aragua, Geremba; 2050 m a.s.1.; 14 Jun. 2008; R. Rouche leg.; AACP • 1 \%; same collection data as for preceding; 18 Oct. 2010; R. Rouche leg.; AACP • 1 §; same collection data as for preceding; 13 May 2016; AACP • 1 万; same collection data as for preceding; 15 Nov. 2017; R. Rouche leg.; AACP.

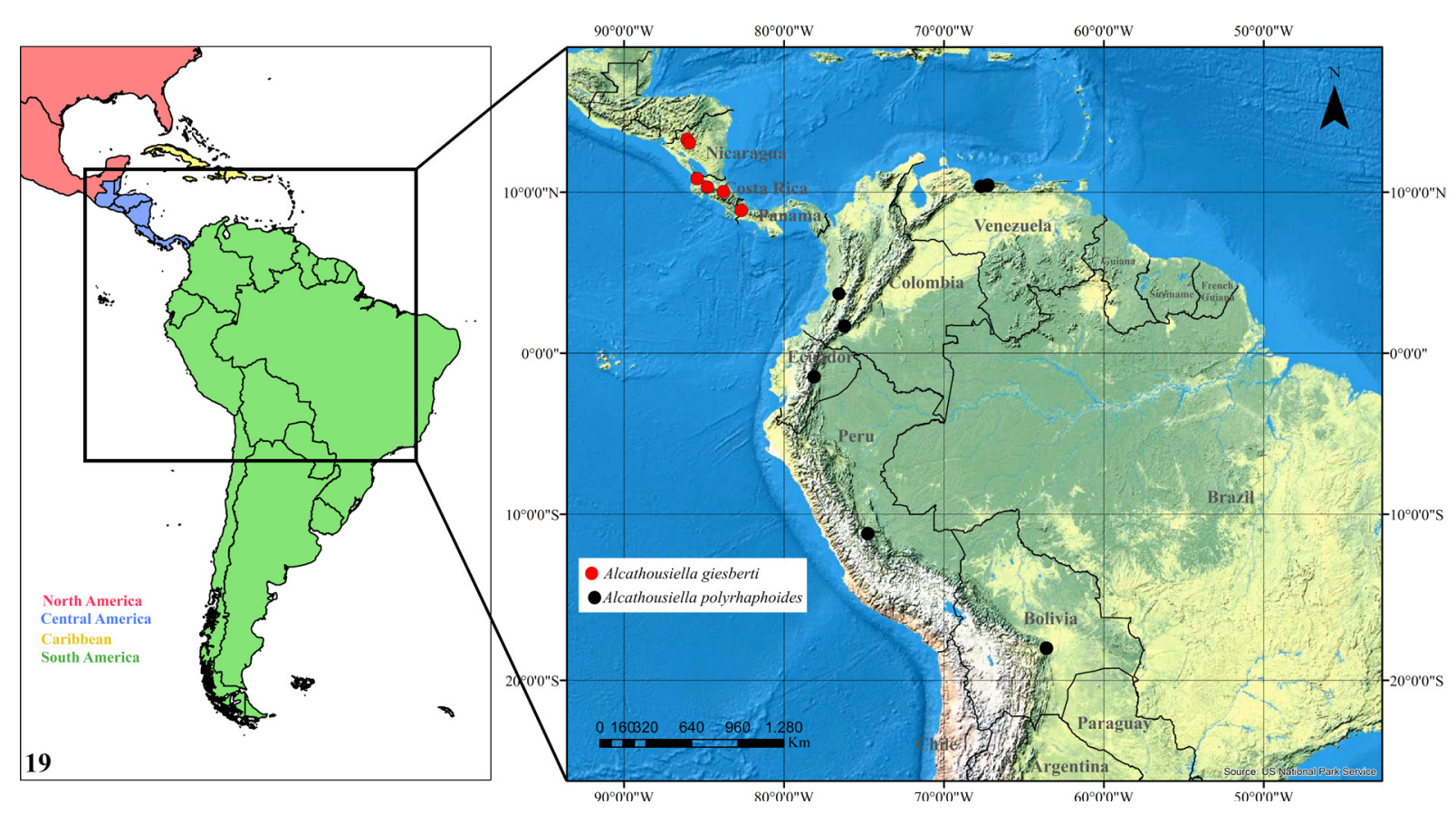

Fig. 19. Map showing the known distribution of species of Alcathousiella Monné, 2005. 


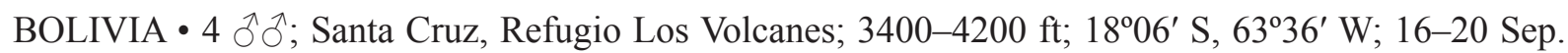
2012; Wappes, Skelley, Bonaso and Hamel leg.; ACMT • 1 \%; same collection data as for preceding; 15 Sep. 2012; ACMT • 1 क; same collection data as for preceding; 25 Oct. 2011; FWSC • 1 §ं; same collection data as for preceding; 27-28 Oct. 2011; ACMT - 2 Oे, 1 क; $4 \mathrm{~km} \mathrm{~N}$ of Bermejo, 1045$1350 \mathrm{ft}, 18^{\circ} 06^{\prime} \mathrm{S}, 62^{\circ} 36^{\prime} \mathrm{W}, 17-24$ Oct. 2014; ACMT • 1 ' ${ }^{\top}$; same collection data as for preceding; 1000-1200 m a.s.1.; $18^{\circ} 06^{\prime}$ S, 62³6' W; 29 Oct. 2011; Wappes and Skillman leg.; ACMT • 1 ภ, 1 \%; same collection data as for preceding; Skillman and Wappes leg.; FWSC • $3 \stackrel{\jmath}{\AA}$; same collection data as for preceding; 12 Dec. 2012; Skillman and Wappes leg.; FWSC • $2 \hat{\jmath}$; same collection data as for preceding; 4 Dec. 2013; Skillman and Wappes leg.; FWSC • 1 क ; same collection data as for preceding; 1000-1200 m a.s.l.; Wappes \& Skillman leg.; ACMT • 1 \%; same collection data as for preceding; 16 Dec. 2013; Skillman and Wappes leg.; FWSC.

PERU • 1 đ̊; Junín, Satipo, Rio Venado Village; 2 May 2018; AACP.

\section{Redescription}

\section{Male}

Colouration. Integument mostly brown, darker brown in some areas. Femoral peduncles, mouthparts with yellowish-brown integument (except mandibles dark brown, blackish toward extremities). Anterior sixth of elytra light brown; anterior two thirds mostly brown (especially on the small scattered tubercles); posterior third slightly yellowish green (vide variability).

HEAD. With dense, greyish pubescence, partially obscuring integument. Lower eye lobe at least 1.2 times as tall as genae length. Upper eye lobes separated by 2.5 times the width of an upper eye lobe.

THORAX. Prosternal process about as wide as $1 / 4$ the procoxal diameter. Mesoventral process about 0.6 of the mesocoxal diameter. Metaventrite with moderately long and dense greyish setae. Scutellum subrounded apically, covered with greyish pubescence in a median line and fuscous on sides.

ELYTRA. With erect yellowish setae on centro-basal crest; elytral surface deeply punctate; elytral apex with outer angle largely triangle projected, sutural angle with minute projection. Pubescence as follows: greyish white band, from humeri converging posteriorly towards suture at elytral middle (not reaching it), with a narrowed band converging forward (reaching suture) forming a W-shaped area; greyish band diverging from angles of $\mathrm{W}$-shaped area to posterior third, towards epipleura; epipleura with small rounded spots of brownish pubescence. Areas between greyish white patch, darkened; posterior third mostly covered by yellowish brown pubescence; with irregular areas of greyish pubescence; elytral fifth with M-shaped area of brownish pubescence.

LEGS. Femora with diameter of clava more than 3 times peduncle diameter; distal half partially covered by greyish pubescence, with a patch of fuscous pubescence; tibiae with greyish pubescence, with a preapical and median ring of fuscous pubescence; metatarsomere I slightly longer than remaining together.

Авdomen. Ventrites with greyish pubescence, denser laterally.

\section{Variability}

The integument coloration at posterior third of elytra varies from dark to light brown (especially in specimens from Venezuela). Also, the greyish pubescence may be denser in some specimens (Fig. 10). The posterior third of elytra varies from slightly yellowish green to light or darker brown. In some specimens (especially those from Peru and Bolivia) the elytral apex may be more angular but not with 
an elongate spine as in $A$. giesberti sp. nov. The posterior M-shaped fascia on elytral fifth is reduced to a transverse band. The femoral peduncles vary from brown to yellow in colour.

Measurements (in mm)

Male/female: total length, 7.7-11.2/7.0-9.0; prothorax length, 1.2-2.6/1.4-2.5; prothorax width, 2.03.5/1.9-2.8; elytral length, 5.2-8.0/5.6-6.2; humeral width, 3.0-5.0/3.4-4.0.

\section{Distribution}

Known from Ecuador and Venezuela; herein it is recorded from Bolivia, Colombia and Peru (new country records) (Fig. 19).

\section{Discussion}

The intraspecific variation of $A$. polyrhaphoides (especially the differences in colour and density of pubescence) may indicate a cline that is possibly a response to different climates. The populations of northern South America and those on the west coast of South America may in fact be two distinct species, but morphologically it is not possible to separate them. Despite the difficulty of understanding what caused the disjunct distribution of the two species of Alcathousiella, a reasonable hypothesis, based on recent studies by O'Dea et al. (2016), can be surmised. Supposedly, the dynamics of varying sea levels during the Pliocene (5.3 Ma to $2.6 \mathrm{Ma}$ ) were likely to have at least temporarily breached the Panama Isthmus, thus interrupting the gene flow between populations of terrestrial animals ( $O^{\prime}$ Dea et al. 2016). It is possible that cladogenesis in the ancestral population of Alcathousiella was caused by a prolonged interruption during this epoch. The current distribution of A. polyrhaphoides can be due in part to an ancestral population which became isolated on the continental side of the Andes Mountains above $1000 \mathrm{~m}$ altitude, an elevated area which was likely little affected by the significant changes in sea level during the Pliocene. Future studies including divergence rates for these species may generate more robust hypotheses about the evolutionary phenomena that acted on the group.

\section{Acknowledgements}

We thank Antonio Santos Silva (MZSP) and Juan Pablo Botero (MZSP) for their valuable comments and suggestions regarding manuscript content. We are also very grateful to Alain Audureau (AACP), Larry Bezark (CSCA), Daniel Heffern (DJHC), Steven Lingafelter (SWLC) and Frederick Skillman (FWSC) who provided us specimens or specimen data from their collections. Similar thanks to the curators who loaned the authors specimens under their care (collection acronyms in Materials and methods). We are also grateful to the curators of the entomological collection Pe. Moure J.S. (DZUP) for permission to use the slides of the Coleção de Imagens de material-tipo J.S. Moure (CITIMOURE). We are also grateful to the anonymous reviewers of this manuscript. The first author is most grateful for the grant 2017/15283-9, from the São Paulo Research Foundation (FAPESP).

Text by the first author: although I did not personally meet the third author, we did some work together and exchanged some funny emails. Here, we pay tribute to James Earl Wappes (July 21, 1944-January 11, 2021), a friend and excellent professional, who inspired me with his taxonomic zeal and his genuinely naturalistic spirit. Thank you, Jim!

\section{References}

Bates H.W. 1863. Contributions to an insect fauna of the Amazon Valley. Coleoptera: Longicornes. The Annals and Magazine of Natural History Series 3 12: 100-109, 275-288, 367-381. https://doi.org/10.1080/00222936308681538 
Bezark L.G. 2020. A Photographic Catalog of the Cerambycidae of the New World. Available from $\mathrm{http} / / /$ bezbycids.com/byciddb/wdefault.asp? $\mathrm{w}=\mathrm{n}$ [accessed 3 Aug. 2020]

Chemsak J.A. \& Linsley E.G. \& Noguera F.A. 1992. Listados Faunísticos de México. II. Los Cerambycidae y Disteniidae de Norteamérica, Centroamérica y las Indias Occidentales (Coleoptera). Universidad Nacional Autónoma México, D.F.

Lacordaire J.T. 1872. Histoire Naturelle des Insectes. Genera des Coléoptères, ou exposé méthodique et critique de tous les genres proposés jusqu'ici dans cet ordre d'insectes. Vol. 9 (2): 411-930. Librairie encyclopédique de Roret, Paris. https://doi.org/10.5962/bhl.title.67686

Lawrence J.F., Beutel R.G., Leschen A.B. \& Ślipinśki A. 2010. 2. Glossary of morphological terms. In: Leschen R.A.B., Beutel R.G. \& Lawrence J.F. (eds) Handbook of Zoology, Arthropoda: Insecta; Coleoptera, Beetles, Vol. 2: Morphology and Systematics (Elateroidea, Bostrichiformia, Cucujiformia partim): 9-20. Walter de Gruyter, Berlin/New York. https://doi.org/10.1515/9783110911213.9

Maes J.M., Berghe E., Dauber D., Audureau A., Nearns E., Skilman F., Heffern D. \& Monné M.A. 2010. Catálogo ilustrado de los Cerambycidae (Coleoptera) de Nicaragua. Parte IV - Lamiinae-Disteniinae. Revista Nicaragüense de Entomología 70 (Supl. 1-4): 1-879.

Monné M.A. 1995. Catalogue of the Cerambycidae (Coleoptera) of the Western Hemisphere. Part XVIII. Subfamily Lamiinae: Tribe Acanthocinini. Sociedade Brasileira de Entomologia, São Paulo.

Monné M.A. 2005. Catalogue of the Cerambycidae (Coleoptera) of the Neotropical Region. Part II. Subfamily Lamiinae. Zootaxa 1023: 1-759. https://doi.org/10.11646/zootaxa.1023.1.1

Monné M.A. 2012. Catalogue of the type-species of the genera of the Cerambycidae, Disteniidae, Oxypeltidae and Vesperidae (Coleoptera) of the Neotropical Region. Zootaxa 3213: 1-183.

https://doi.org/10.11646/zootaxa.3213.1.1

Monné M.A. 2020. Catalogue of the Cerambycidae (Coleoptera) of the Neotropical region. Part I. Subfamily Cerambycinae. Available from https://cerambycids.com/catalog [accessed 3 Aug. 2020]

Nascimento F.E. de L. \& Botero J.P. 2019. The Neotropical genera of Acanthocinini Blanchard, 1845 (Coleoptera: Cerambycidae: Lamiinae) with the third antennomere modified. Annales de la Société entomologique de France (N.S.) 55 (5): 410-418. https://doi.org/10.1080/00379271.2019.1636716

O’Dea A., Lessios H.A., Coates A.G., Eytan R.I., Restrepo-Moreno S.A., Cione A.L., Collins L.S., de Queiroz A., Farris D.W., Norris R.D., Stallard R.F., Woodburne M.O., Aguilera O., Aubry M.-P., Berggren W.A., Budd A.F., Cozzuol M.A., Coppard S.E., Duque-Caro H., Finnegan S., Gasparini G.M., Grossman E.L., Johnson K.G., Keigwin L.D., Knowlton N., Leigh E.G., Leonard-Pingel J.S., Marko P.B., Pyenson N.D., Rachello-Dolmen P.G., Soibelzon E., Soibelzon L., Todd J.A., Vermeij G.J. \& Jackson B.C. 2016. Formation of the Isthmus of Panama. Science Advances 2 (8): e1600883.

https://doi.org/10.1126/sciadv.1600883

Swift I.P., Bezark L.G., Nearns E.H., Solís A. \& Hovore F.T. 2010. Checklist of the Cerambycidae (Coleoptera) of Costa Rica. Insecta Mundi 0131: 1-68.

Tavakilian G.L. \& Chevillotte H. 2020. Titan: base de données internationales sur les Cerambycidae ou Longicornes. Version 3.0. Available from http://titan.gbif.fr [accessed 3 Aug. 2020].

Thomson J. 1864. Systema Cerambycidarum ou exposé de tous les genres compris dans la famille des Cérambycides et familles limitrophes. Mémoires de la Société royale des Sciences de Liège 19: 1-540. https://doi.org/10.5962/bhl.title.48458

Thomson J. 1865. Diagnoses d'espèces nouvelles qui seront décrites dans l'appendix du systema cerambycidarum. Mémoires de la Société royale des Sciences de Liège 19: 541-578. 
White A. 1855. Catalogue of the Coleopterous Insects in the Collection of the British Museum. Part VIII. Longicornia II. Trustees of the British Museum, London.

https://doi.org/10.5962/bhl.title.60043

Manuscript received: 3 October 2020

Manuscript accepted: 12 April 2021

Published on: 28 June 2021

Topic editor: Nesrine Akkari

Section editor: Max Barclay

Desk editor: Pepe Fernández

Printed versions of all papers are also deposited in the libraries of the institutes that are members of the EJT consortium: Muséum national d'histoire naturelle, Paris, France; Meise Botanic Garden, Belgium; Royal Museum for Central Africa, Tervuren, Belgium; Royal Belgian Institute of Natural Sciences, Brussels, Belgium; Natural History Museum of Denmark, Copenhagen, Denmark; Naturalis Biodiversity Center, Leiden, the Netherlands; Museo Nacional de Ciencias Naturales-CSIC, Madrid, Spain; Real Jardín Botánico de Madrid CSIC, Spain; Zoological Research Museum Alexander Koenig, Bonn, Germany; National Museum, Prague, Czech Republic. 